\title{
Reduction of acute toxicity and genotoxicity of dye effluent using Fenton-coagulation process
}

Jing Zhang, Shuo Chen, Ying Zhang, Xie Quan*, Huimin Zhao, Yaobin Zhang

Key Laboratory of Industrial Ecology and Environmental Engineering (Ministry of Education), School of Environmental Science and Technology, Dalian University of Technology, Linggong Road 2, Dalian 116024, P. R. China

*Corresponding author: Xie Quan

Tel: +86-411-84706140; fax: +86-411-84706263

E-mail address: quanxie@dlut.edu.cn (X. Quan)

\begin{abstract}
Dye wastewater exhibits significant ecotoxicity even though its physico-chemical parameters meet the discharge standards. In this work, the acute toxicity and genotoxicity of dye effluent were tested, and the Fenton-coagulation process was carried out to detoxify this dye effluent. The acute toxicity was evaluated according to the mortality rate of zebrafish, and genotoxicity was evaluated by micronucleus (MN) and comet assays. Removal of color and chemical oxygen demand (COD) was also investigated. The results indicated that the dye effluent showed strong acute toxicity and genotoxicity to zebrafish. After $4 \mathrm{~h}$ of treatment by Fenton-coagulation process, the dye effluent exhibited no significant acute toxicity and genotoxicity to zebrafish. In addition, its COD was less than $50 \mathrm{mg} / \mathrm{L}$, which met the discharge standard. It demonstrates that Fenton-coagulation process can comprehensively reduce the acute toxicity and genotoxicity as well as the COD of the dye effluent.
\end{abstract}


Keywords: Acute toxicity; COD; Dye effluent; Fenton-coagulation; Genotoxicity

\section{Introduction}

Dye wastewater, containing high concentrations of unfixed dyes, salts and other organic compounds, is one of the major industrial water pollution sources in developing countries [1]. More than $1.6 \times 10^{9} \mathrm{~m}^{3}$ dye wastewater is generated annually in China [2]. Azo dyes are one of the most common pollutants in the dye wastewater. Moreover, they are recalcitrant to be degraded by conventional biological wastewater treatment methods. Azo dyes have attracted more attention on its intermediates, especially aromatic amines, produced under anaerobic conditions and cannot be entirely removed by aerobic biological process. Aromatic amines were considered to be more toxic than azo dyes for their carcinogenic effect to aquatic life [3-5]. Consequently, effective treatment processes needs to be applied in the treatment of dye wastewater. Different kinds of treatment processes have been applied to treat this wastewater [6-9]. Advanced oxidation processes (AOPs) are efficient methods to degrade refractory organic pollutants, since they can generate the powerful oxidant, - $\mathrm{OH}\left(\mathrm{E}^{\circ}=2.8 \mathrm{~V}\right)$, without selectivity for most organic compounds [10]. Among the AOPs, Fenton process has gained increasing attention with its simple equipment, mild operating conditions (room temperature and atmospheric pressure) and effective $\bullet \mathrm{OH}$ generation [10, 11]. The Fenton reaction mechanism is that $\mathrm{H}_{2} \mathrm{O}_{2}$ decomposes catalytically by $\mathrm{Fe}^{2+}$ to form the $\cdot \mathrm{OH}$ at acidic $\mathrm{pH}$ (Equation (1)), which can oxidize most organic matter into harmless compounds such as $\mathrm{CO}_{2}, \mathrm{H}_{2} \mathrm{O}$, and some organic acids such as formic acid, acetic, and oxalic acids [11]. Additionally, $\mathrm{Fe}^{3+}$ can catalyze the $\mathrm{H}_{2} \mathrm{O}_{2}$ in the so-called Fenton-like reaction, regenerating $\mathrm{Fe}^{2+}$, thus the process is sustaining via Equations (2)-(8) [12].

$$
\begin{aligned}
& \mathrm{Fe}^{2+}+\mathrm{H}_{2} \mathrm{O}_{2} \rightarrow \cdot \mathrm{OH}+\mathrm{OH}^{-}+\mathrm{Fe}^{3+} \\
& \mathrm{Fe}^{3+}+\mathrm{H}_{2} \mathrm{O}_{2} \rightarrow \mathrm{Fe}^{2+}+\mathrm{H}^{+}+\mathrm{HOO} \bullet \\
& \mathrm{Fe}^{3+}+\mathrm{HOO} \bullet \rightarrow \mathrm{Fe}^{2+}+\mathrm{H}^{+}+\mathrm{O}_{2}
\end{aligned}
$$


$\mathrm{Fe}^{2+}+\cdot \mathrm{OH} \rightarrow \mathrm{Fe}^{3+}+\mathrm{OH}^{-}$

$\cdot \mathrm{OH}+\mathrm{H}_{2} \mathrm{O}_{2} \rightarrow \mathrm{H}_{2} \mathrm{O}+\mathrm{HOO} \cdot$

$\mathrm{Fe}^{2+}+\mathrm{HOO} \cdot \rightarrow \mathrm{HOO}^{-}+\mathrm{Fe}^{3+}$

$\cdot \mathrm{OH}+\cdot \cdot \mathrm{OH} \rightarrow \mathrm{H}_{2} \mathrm{O}_{2}$

$\cdot \mathrm{OH}+$ organics $\rightarrow$ products $+\mathrm{CO}_{2}+\mathrm{H}_{2} \mathrm{O}$

Both $\mathrm{Fe}^{2+}$ and $\mathrm{Fe}^{3+}$ ions are coagulants, simultaneous occurrence of oxidation and coagulation, can be obtained by adjusting $\mathrm{pH}$ in Fenton-coagulation process. It can achieve better removal of target compounds, color, and COD, than the Fenton process $[10,13,14]$.

Little attention has been paid to assess the ecotoxicity of biologically treated dye effluent, when the chemical parameters of it meet the standard. Previous study has shown that despite of the reduction of color, COD and TOC, the wastewater ecotoxicity cannot be significantly reduced, even can be potentially increased [15-17]. Therefore, it is essential to evaluate dye effluent ecotoxicity for their potential risks to ecosystems. Acute toxicity is frequently used to reflect the ecotoxicity of wastewater to organisms exposed in them $[18,19]$. Besides, the genotoxicity is of special concern, because it may cause adverse reproductive damage to organisms directly or even lead to their extinction [7, 20]. These two kinds of biological monitoring combined together can provide a relative comprehensive evaluation of the toxic hazard of wastewater on natural environments.

In this work, we assessed the chemical parameters and acute toxicity and genotoxicity of effluent from an industrial dye wastewater treatment plant (WwTP), and investigated the detoxification efficiency of Fenton-coagulation process in this real dye effluent treatment. Combination of chemical and biological analysis can provide comprehensive evaluation of dye effluent in order to avoid potential ecological risks. Furthermore, Fenton-coagulation process has been proven to be effective on detoxification of real dye effluent. 


\section{Materials and methods}

\subsection{Synthetic dye effluent}

The active red azo dye 3BS and sucrose were dissolved in tap-water to prepared the synthetic effluent. The chemical formula of dye 3BS is shown in Fig.1 [21]. The final concentrations of dye and COD in synthetic dye effluent were $10 \mathrm{mg} / \mathrm{L}\left(9.21 \times 10^{-3}\right.$ $\mathrm{mM}$ ) and $100 \mathrm{mg} / \mathrm{L}$, respectively, which are close to those of real industrial dye effluent.

\subsection{Real dye effluent}

According to 24-h composite sampling method [22], the real dye effluent samples were collected from an industrial wastewater treatment plant of the textile factory (Liaoning, China) used dye 3BS as original materials. Samples were transported to the laboratory immediately and kept at $4{ }^{\circ} \mathrm{C}$ without any chemicals addition before analysis. Water quality of real dye effluent is given in Table 1.

\subsection{Fenton process}

The Fenton process was carried out in 5-L glass bottles at room temperature and atmospheric pressure. The initial $\mathrm{pH}$ of the sample was manually adjusted to 3 with 1 $\mathrm{M} \mathrm{H}_{2} \mathrm{SO}_{4}$. Then the Fenton regent was added in the reactor. The $\mathrm{Fe}^{2+}$ dose was varied between 0.18 to $0.9 \mathrm{mM} . \mathrm{H}_{2} \mathrm{O}_{2}$ was varied between $1.08 \mathrm{mM}$ and $8.64 \mathrm{mM}$ (0.18 to 1.5 times stoichiometric amount with respect to COD).

\subsection{Coagulation process}

Samples from each time interval of Fenton process were adjusted $\mathrm{pH}$ to 7 with $1 \mathrm{M}$ $\mathrm{NaOH}$ for coagulation process.

\subsection{Chemical analysis}

COD, biological oxygen demand (BOD), $\mathrm{NH}_{4}{ }^{+}-\mathrm{N}$, suspended solid (SS), total nitrogen (TN) and total phosphorus (TP) were determined according to the APHA standard methods [23]. The $\mathrm{pH}$ was measured by a $\mathrm{pH}$ analyzer. TOC was determined by a TOC analyzer (Shimadzu, TOC- $\mathrm{V}_{\mathrm{CPH}}$, Japan). The color level was measured by the dilution times method [24]. The concentration of 3BS was measured by UV-vis 
spectrophotometer (Techcomp, UV-2301, China) at $541 \mathrm{~nm}$ [25]. $\mathrm{H}_{2} \mathrm{O}_{2}$ concentration was determined by a spectrophotometric method as previously described [26].

\subsection{Toxicity tests}

\subsubsection{Acute toxicity test}

The $96 \mathrm{~h}$ acute-static toxicity test was done as previously described [27]. Zebrafish (Tuebingen strain, 3-6 months old) were exposed to different dilution volume ratios of effluent samples (5\%, 10\%, 25\%, 50\%, 75\% and 100\%) in triplicate. Potassium dichromate (> $30 \mathrm{mg} / \mathrm{L}$ ) and 4-nitroquinoline-1-oxide (4-NQO) (> $60 \mathrm{mg} / \mathrm{L}$ ) were set as positive controls.

\subsubsection{Genotoxicity assays}

The genotoxicity was assessed by $\mathrm{MN}$ and comet assays upon the zebrafish exposed to effluent samples for 96 h. Potassium dichromate (2.5, 5, 10 and $20 \mathrm{mg} / \mathrm{L})$ and 4-NQO (20, 30, 40 and $50 \mathrm{mg} / \mathrm{L}$ ) were set as positive controls (Fig. S1 and S2), meanwhile, uncontaminated dechlorinated tap water was set as negative control (NC). The dechlorinated tap water treated by Fenton-coagulation process was set as Fenton-coagulation process control (FC).

MN assay: Zebrafish blood was smeared on clean slides containing fetal bovine serum by making a caudal cut. Slides were air-dried, fixed in methanol and then stained in 10\% Giemsa's stain. MN frequency was observed in the light microscope under oil immersion $(10 \times 100$ magnification) [15].

Comet assay: Liver cells of zebrafish were used for the comet assay. Rough microscope slides were first coated with $1 \%$ normal melting point agarose (NMP) and solidified on ice. The supportive (second) agarose layer covered with $0.7 \%$ low melting point (LMP) agarose at a ratio of 1 part cells to 3 parts agarose to prevent the nuclear DNA from escaping during cell lysis and electrophoresis. The lysis of cells was carried out by incubating the microgels for $1.5 \mathrm{~h}$ at $4{ }^{\circ} \mathrm{C}$ in fresh lysis solution. The microgels were then submerged into a $4{ }^{\circ} \mathrm{C}$ alkaline electrophoresis buffer (300 $\mathrm{mM} \mathrm{NaOH}, 1 \mathrm{mM}$ EDTA, $\mathrm{pH}$ 13) for 20 min to unwind the nuclear DNA. Afterwards 
the microgels were placed side by side into an electrophoresis chamber containing an electrophoresis buffer. Electrophoresis was performed at $25 \mathrm{~V}, 300 \mathrm{~mA}$ for $20 \mathrm{~min}$. Following electrophoresis, the microgels were neutralized in a freshly prepared 400 $\mathrm{mM}$ Tris-HCl buffer (pH 7.5) for 15 min for three times. The DNA was stained with Gelred $(0.2 \mu \mathrm{L} / \mathrm{mL})$ before microscope analysis. Tail moment was used as the measure of DNA damage [15].

\subsection{Statistical analysis}

Tail moment was quantified using the image analysis program Casp 1.2.2 (Zbigniew Koza, Poland). The results were expressed as the mean \pm SD. Statistically significant differences among means were determined by one-way analysis of variance (ANOVA) followed by Dunnett's test with significance at $\mathrm{p}<0.05$ for all tests.

\section{Results and discussion}

\subsection{Application of Fenton-coagulation process on synthetic effluent}

3.1.1. Color and COD removal of synthetic effluent by Fenton-coagulation process

Before treating the real dye effluent, the operation conditions and effectiveness of Fenton-coagulation process were investigated through treating the synthetic dye effluent. The effect of $\mathrm{Fe}^{2+}$ dose on 3BS and COD removal was investigated at the initial conditions: $4.32 \mathrm{mM} \mathrm{H} \mathrm{H}_{2}$ and $\mathrm{pH}=3$ (data not shown). The 3BS and COD removal efficiencies were increased when the $\mathrm{Fe}^{2+}$ dose increased from $0.18 \mathrm{mM}$, and reached maximum efficiencies (97\% and 73\%, respectively) at $\mathrm{Fe}^{2+}$ dose of $0.36 \mathrm{mM}$, and then declined when the dose of $\mathrm{Fe}^{2+}$ got higher than $0.36 \mathrm{mM}$. In subsequent studies, the initial $\mathrm{Fe}^{2+}$ dose was selected at $0.36 \mathrm{mM}$.

$\mathrm{H}_{2} \mathrm{O}_{2}$ plays an important role as an oxidant in the Fenton reaction for generating the -OH. To optimize the dose of $\mathrm{H}_{2} \mathrm{O}_{2}$ in Fenton process, Fenton reagent ratio $\left(\mathrm{M}\left[\mathrm{H}_{2} \mathrm{O}_{2}\right]: \mathrm{M}\left[\mathrm{Fe}^{2+}\right]\right)$ from $3: 1$ to $24: 1\left(1.08 \mathrm{mM}\right.$ to $\left.8.64 \mathrm{mM} \mathrm{H} \mathrm{O}_{2}\right)$ under $0.36 \mathrm{mM}$ $\mathrm{Fe}^{2+}$ at $\mathrm{pH} 3$ was investigated. It showed that $97 \%$ of $3 \mathrm{BS}$ and $73 \%$ of COD could be 
removed at the initial Fenton reagent ratio up to 12:1 (Fig. 2) since the presence of enough $\mathrm{H}_{2} \mathrm{O}_{2}$ catalyzed by $\mathrm{Fe}^{2+}$ for producing more $\cdot \mathrm{OH}$ (Equation 1). However, decrements of 3BS and COD removal were observed when the Fenton reagent ratio was higher than 12:1 (data not shown), since the redundant $\mathrm{H}_{2} \mathrm{O}_{2}$ might scavenge $\bullet \mathrm{OH}$ (Equation 5).

Then the coagulation process after Fenton process was investigated on the synthetic effluent. The 3BS and COD removal efficiencies were increased up to $99 \%$ and $80 \%$ by this process, respectively. The reason was that the formation of iron hydroxides, which could adsorb organic matters in the solution, led to the decrease of 3BS and COD [28].

\subsection{2. $\mathrm{H}_{2} \mathrm{O}_{2}$ decomposition in Fenton and Fenton-coagulation processes}

In Fenton and Fenton-coagulation processes, $\mathrm{H}_{2} \mathrm{O}_{2}$ may appear as a residue at the end of treatment and contribute to relatively higher toxicity than that of $\mathrm{Fe}^{2+}[29,30]$. Hence, the dose of $\mathrm{H}_{2} \mathrm{O}_{2}$ during the treatment was investigated as shown in Fig. 3. At the first stage of the reaction, the consumption rate of $\mathrm{H}_{2} \mathrm{O}_{2}$ was fast with the main reaction catalyzed by $\mathrm{Fe}^{2+}$. Then the consumption rate of $\mathrm{H}_{2} \mathrm{O}_{2}$ got slow with the main reaction catalyzed by $\mathrm{Fe}^{3+}$ [11]. The $\mathrm{H}_{2} \mathrm{O}_{2}$ consumption was related to COD and 3BS removal in the synthetic effluent since $\cdot \mathrm{OH}$ from $\mathrm{H}_{2} \mathrm{O}_{2}$ catalyzed by $\mathrm{Fe}^{2+}$ could oxidize the organic compounds. The coagulation process also reduced the $\mathrm{H}_{2} \mathrm{O}_{2}$ concentration, probably due to the increment of $\mathrm{pH}$ enhancing the decomposition of $\mathrm{H}_{2} \mathrm{O}_{2}$ into $\mathrm{O}_{2}$ and $\mathrm{H}_{2} \mathrm{O}$ as well as the adsorption of $\mathrm{H}_{2} \mathrm{O}_{2}$ on ferric hydroxide gel.

\subsubsection{Acute toxicity of the synthetic effluent}

To clarify the potential risk of synthetic effluent during Fenton-coagulation process, the evolution of acute toxicity was investigated (Table 2). The NC and FC did not pose any acute toxicity to zebrafish. The acute toxicity of synthetic effluent showed specific dose-dependence. The Fenton-coagulation process resulted in the augmentation of acute toxic effects on zebrafish at initial periods of the process. At Fenton reagent ratio of $3: 1$, the mortality rate increased from $8 \%$ to about $23 \%$ after 
$0.5 \mathrm{~h}$ treatment, and was not reduced by extending treatment time. However, at Fenton reagent ratio of $6: 1$ and $12: 1$, the acute toxicity, increasing to $65 \%$ and $25 \%$ after $0.5 \mathrm{~h}$ treatment, was removed by extending treatment time. It implied that the formation of intermediate products was more toxic than their parent compounds, and could be degraded by Fenton-coagulation process in enough reaction time at the appropriate Fenton reagent ratio. Moreover, a faster degradation rate was achieved at Fenton reagent ratio of $12: 1$ than that of $6: 1$ because of higher amount of $\bullet \mathrm{OH}$ produced. Therefore, the acute toxicity removal of synthetic effluent depended on the Fenton reagent ratio. Furthermore, the coagulation process also promoted the acute toxicity removal through the sedimentation of toxic pollutants.

\subsubsection{Genotoxicity of the synthetic effluent}

Dye effluent may bring potential damage to the chromosome and DNA of organisms. MN and comet assays were used to characterize the genotoxicity of synthetic dye effluent after Fenton-coagulation process, and the results were shown in Fig. 4. The genotoxicity of FC at each interval was not significantly different from that of NC, thus residues of Fenton-coagulation process do not contribute to the genotoxicity. All the synthetic effluent samples before and during Fenton-coagulation process did not exhibit any acute toxicity at $25 \%$ dilution while some of them displayed significant acute toxicity without dilution. So in the genotoxicity removal experiments, the genotoxicity of the synthetic effluent samples were performed at $25 \%$ dilution to avoid the interference by the acute toxicity. The results showed that the raw synthetic effluent induced a strong genotoxicity response toward zebrafish assessed by both MN and comet assays. The effluent treated by Fenton-coagulation process at all three Fenton reagent ratios caused significant increase in genotoxicity at the initial stage of process. However, the genotoxicity decreased during the treatment at Fenton reagent ratio of $6: 1$ and $12: 1$, achieving $46 \%$ and $79 \%$ reduction of $\mathrm{MN}$ frequency, and $30 \%$ and $77 \%$ reduction of tail moment, except for the samples treated at Fenton reagent ratio of 3:1, which presented no decrease in the genotoxicity for 
even $4 \mathrm{~h}$ treatment. The genotoxicity evolution was probably due to the rapid transformation of compounds in synthetic effluent into more toxic intermediates and the subsequent degradation of the intermediates into inorganic compounds and organic acids with low genotoxicity [31]. Increasing initial Fenton reagent ratio enhanced the genotoxicity reduction with the formation of more $\cdot \mathrm{OH}$ that could oxidize the synthetic effluent and its intermediates. In addition, the Fenton-coagulation process could achieve a better detoxification by oxidation and sedimentation of the toxic contaminants than Fenton process.

\subsection{Application of Fenton-coagulation process on real effluent}

\subsubsection{COD evolution of real effluent}

According to Chinese Sewage Discharge Standard (GB4287-2012), only color, BOD, SS and $\mathrm{pH}$ parameters are regulated. The levels of COD, TP, TN and $\mathrm{NH}_{4}{ }^{+}-\mathrm{N}$ in real effluent are beyond the discharge standards as shown in Table 1. The BOD/COD ratio of real dye effluent $(<0.3)$ was rather low implying its low biodegradability. Therefore, Fenton-coagulation as an alternative advanced treatment process was attempted to treat this type of effluent aiming to meet the discharge standard.

From the part of 3.1., it showed that the acute toxicity and genotoxicity of synthetic effluent could not be removed and even increased at low Fenton reagent ratio of 3:1 (Table 2 and Fig. 4). Here, the initial conditions of Fenton-coagulation process were

$0.36 \mathrm{mM} \mathrm{Fe}^{2+}, \mathrm{pH}=3$, and Fenton reagent ratios varying at 6:1 and 12:1 (Fig. 5). The results indicated that increasing the Fenton reagent ratio from 6:1 to 12:1 could improve COD removal. At Fenton reagent ratio of 6:1, 38\% and 56\% COD removal were achieved in Fenton and Fenton-coagulation process, respectively, while at Fenton reagent ratio of $12: 1,51 \%$ and $65 \%$ COD could be removed in Fenton and Fenton-coagulation process, respectively. The final COD of real effluent all met the Chinese Sewage Discharge Standard $(<50 \mathrm{mg} / \mathrm{L})$, except that of the effluent treated by Fenton process at Fenton reagent ratio of 6:1. In Fenton process, the dose of Fenton reagent was in direct proportion to the COD removal. In coagulation process, 
COD removal could be further increased by the emergence of iron flocs deposits. The COD removal of real effluent treated by Fenton-coagulation process was much lower than that of synthetic effluent. It probably resulted from undesirable side reactions that occurred between the $\bullet \mathrm{OH}$ and anions present in the real effluent, such as chlorides, carbonates, sulfates and so on [32].

\subsection{2. $\mathrm{H}_{2} \mathrm{O}_{2}$ decomposition during the Fenton and Fenton-coagulation processes}

The $\mathrm{H}_{2} \mathrm{O}_{2}$ concentration in the real effluent treated at Fenton reagent ratios of 6:1 and 12:1 by Fenton and Fenton-coagulation process were measured (Fig. 6). It decreased continually until completely exhausted. The consumption of $\mathrm{H}_{2} \mathrm{O}_{2}$ was related to the reaction of $\mathrm{H}_{2} \mathrm{O}_{2}$ and $\mathrm{Fe}^{2+}$, producing $\bullet \mathrm{OH}$ and consequently achieving a high efficiency of COD removal as shown in Fig. 5. Subsequently, the coagulation process also promoted the $\mathrm{H}_{2} \mathrm{O}_{2}$ consumption for the adsorption of $\mathrm{H}_{2} \mathrm{O}_{2}$ on the oxyhydroxides formed by $\mathrm{Fe}^{3+}$ precipitation.

\subsubsection{Acute toxicity of real effluent}

In some cases, the COD removal does not show significant toxicity reduction after advanced treatments, or the intermediates cause more toxicity than their parent compounds [33-37], so it is necessary to carry out further toxicity tests. The real effluent from the dye WwTP showed acute toxicity to zebrafish with mortality rate of about $17 \%$ (Table 3). At Fenton reagent ratio of $6: 1$, the mortality rate of zebrafish was increased to $30 \%$ when the real effluent was treated by Fenton-coagulation process for $1 \mathrm{~h}$. With extending treatment time, a fast decrease of acute toxicity was observed. The increased acute toxicity at initial stage was probably due to the production of intermediates with more toxicity to zebrafish as literature reported [38]. The acute toxicity decreased rapidly at Fenton reagent ratio of 12:1, achieving no inhibition of zebrafish survival after $1 \mathrm{~h}$ treatment. It was implied that more $\bullet \mathrm{OH}$ generated attacked the organic matters through the reaction of $\mathrm{Fe}^{2+}$ and $\mathrm{H}_{2} \mathrm{O}_{2}$ (Equation 1).

\subsubsection{Genotoxicity of real effluent}


Table 3 demonstrated that effluent exhibited significant acute toxicity without dilution while it had no acute toxicity with $75 \%$ dilution. Accordingly, the genotoxicity of the real effluent were tested at $75 \%$ dilution for avoiding the interference of acute toxicity. The genotoxicity of real effluent before and after Fenton-coagulation process was tested as shown in Fig. 7. The raw real effluent sample without treatment induced high genotoxicity for the zebrafish. Based on the MN assay (Fig. 7 (a)), at Fenton reagent ratio of 6:1, the genotoxicity of real effluent increased in the initial $1 \mathrm{~h}$ and only $41 \%$ of genotoxicity was reduced after $4 \mathrm{~h}$ treatment by Fenton-coagulation process. At Fenton reagent ratio of 12:1, the rising tendency of genotoxicity in the initial $1 \mathrm{~h}$ was also observed, however, the genotoxicity decreased fast and was not significantly different from NC after 4 h since more $\bullet \mathrm{OH}$ was produced.

Based on the comet assay (Fig. 7 (b)), at Fenton reagent ratio of 6:1, the genotoxicity of the real effluent remained nearly unchanged during the initial $1 \mathrm{~h}$ treatment and was significantly removed from 1 to 4 h. At Fenton ratio of 12:1, the genotoxicity was reduced to almost the same level as NC after $4 \mathrm{~h}$ treatment. The genotoxicity removal efficiency was higher at the ratio of $12: 1$ than that of $6: 1$. Therefore, Fenton reagent ratio of 12:1 was the appropriate condition for genotoxicity removal.

The MN assay demonstrated that the genotoxicity of real effluent treated by Fenton-coagulation for $1 \mathrm{~h}$ was higher than that of raw real effluent; but the comet assay showed the contrary results on genotoxicity. In some cases, $\mathrm{MN}$ and comet assays achieved the different results on genotoxicity for the different mechanisms of these two bioassays. The MN assay is related to chromosome aberrations in a meiotic or mitotic division, such as losses [39]. The comet assay examines DNA strand breaks and alkali labile sites (single and double-strand breaks) by measuring the migration of DNA from immobilized nuclear DNA [40]. Besides, the MN and comet assays employed the different body tissues of zebrafish, peripheral blood and liver, 
respectively. Therefore, both bioassays taken into account can give an overall evaluation of the potential genotoxicity.

The ecotoxicity data suggest it is not appropriate simply relying on chemical estimates in wastewater risk [41]. Chemical analyses combined with ecotoxicity bioassays can draw a comprehensive assessment of wastewater risk. It can provide a scientific basis for wastewater discharge standards and a scientific technology for detoxification.

\section{Conclusions}

The chemical parameters, acute toxicity and genotoxicity of synthetic and real dye effluent were investigated and detoxification of both kinds of effluent was achieved using Fenton-coagulation process. For synthetic effluent, 99\% of color and $80 \%$ of COD were removed under the conditions of $\mathrm{Fe}^{2+}$ dose of $0.36 \mathrm{mM}$ and Fenton reagent ratio of 12:1 at pH 3 after 4 h treatment, meanwhile, the acute toxicity was completely removed and the genotoxicity was reduced to almost the same level as NC. For real dye effluent, COD with removal efficiency up to $65 \%$ was $33.6 \mathrm{mg} / \mathrm{L}$, which met the Chinese Sewage Discharge Standard. The acute toxicity was completely removed, and the genotoxicity was reduced to the same level as NC and FC after $4 \mathrm{~h}$ of treatment. Taking together, this work demonstrated that Fenton-coagulation process can provide comprehensive treatment for mineralization and detoxification of dye effluent. Moreover, this study also illustrates the essential need for a battery of bioassays in ecological risk assessment of effluent.

\section{Acknowledgement}

The research was supported by the National Natural Science Foundation of China (NSFC-JST 21261140334) and National Science and Technology Major Project Water Pollution Control and Treatment (No. 2012ZX07202006-004). 


\section{Appendix A. Supplementary data}

Supplementary data associated with this article can be found, in the online version, at

\section{References}

[1] S.H. Chang, S.H. Chuang, H.C. Li, H.H. Liang, L.C. Huang, Comparative study on the degradation of I.C. Remazol Brilliant Blue R and I.C. Acid Black 1 by Fenton oxidation and $\mathrm{Fe}^{0}$ /air process and toxicity evaluation, J. Hazard. Mater. 166 (2009) 1279-1288.

[2] X. Zhu, J. Ni, J. Wei, X. Xing, H. Li, Destination of organic pollutants during electrochemical oxidation of biologically-pretreated dye wastewater using boron-doped diamond anode, J. Hazard. Mater. 189 (2011) 127-133.

[3] J. Garcia-Montano, X. Domenech, J.A. Garcia-Hortal, F. Torrades, J. Peral, The testing of several biological and chemical coupled treatments for Cibacron Red FN-R azo dye removal, J. Hazard. Mater. 154 (2008) 484-490.

[4] M. Jonstrup, M. Punzi, B. Mattiasson, Comparison of anaerobic pre-treatment and aerobic post-treatment coupled to photo-Fenton oxidation for degradation of azo dyes, J. Photoch. Photobio. A 224 (2011) 55-61.

[5] H.M. Pinheiro, E. Touraud, O. Thomas, Aromatic amines from azo dye reduction: status review with emphasis on direct UV spectrophotometric detection in textile industry wastewaters, Dyes Pigment 61 (2004) 121-139.

[6] S. Meriç, H. Selçuk, V. Belgiorno, Acute toxicity removal in textile finishing wastewater by Fenton's oxidation, ozone and coagulation-flocculation processes, Water Res. 39 (2005) 1147-1153.

[7] S. Vanhulle, M. Trovaslet, E. Enaud, M. Lucas, S. Taghavi, D. van der Lelie, B. van Aken, M. Foret, R.C.A. Onderwater, D. Wesenberg, S.N. Agathos, Y.-J. Schneider, A.-M. Corbisier, Decolorization, cytotoxicity, and genotoxicity reduction during a combined ozonation/fungal treatment of dye-contaminated wastewater, Environ. Sci. Technol. 42 (2007) 584-589.

[8] F. Zhang, A. Yediler, X. Liang, Decomposition pathways and reaction intermediate formation of the purified, hydrolyzed azo reactive dye C.I. Reactive Red 120 during ozonation, Chemosphere 67 (2007) 712-717. 
[9] S.M.d.A.G.U. de Souza, K.A.S. Bonilla, A.A.U. de Souza, Removal of COD and color from hydrolyzed textile azo dye by combined ozonation and biological treatment, J. Hazard. Mater. 179 (2010) 35-42.

[10] J.A. Zazo, J.A. Casas, C.B. Molina, A. Quintanilla, J.J. Rodriguez, Evolution of ecotoxicity upon Fenton's oxidation of phenol in water, Environ. Sci. Technol. 41 (2007) 7164-7170.

[11] N. Masomboon, C. Ratanatamskul, M.C. Lu, Chemical oxidation of 2,6-dimethylaniline in the Fenton process, Environ. Sci. Technol. 43 (2009) 8629-8634.

[12] J.J. Pignatello, Dark and photoassisted $\mathrm{Fe}^{3+}$-catalyzed degradation of chlorophenoxy herbicides by hydrogen-peroxide, Environ. Sci. Technol. 26 (1992) 944-951.

[13] M.I. Badawy, M.E.M. Ali, Fenton's peroxidation and coagulation processes for the treatment of combined industrial and domestic wastewater, J. Hazard. Mater. 136 (2006) 961-966.

[14] S.-F. Kang, C.-H. Liao, M.-C. Chen, Pre-oxidation and coagulation of textile wastewater by the Fenton process, Chemosphere 46 (2002) 923-928.

[15] J. Zhang, Y. Zhang, W. Liu, X. Quan, S. Chen, H. Zhao, Y. Jin, W. Zhang, Evaluation of removal efficiency for acute toxicity and genotoxicity on zebrafish in anoxic-oxic process from selected municipal wastewater treatment plants, Chemosphere 90 (2013) 2662-2666.

[16] W. Zhang, W. Liu, J. Zhang, H. Zhao, Y. Zhang, X. Quan, Y. Jin, Characterisation of acute toxicity, genotoxicity and oxidative stress posed by textile effluent on zebrafish, J. Environ. Sci.-China 24 (2012) 2019-2027.

[17] T.W. Ma, X.Q. Wan, Q.H. Huang, Z.J. Wang, J.K. Liu, Biomarker responses and reproductive toxicity of the effluent from a Chinese large sewage treatment plant in Japanese medaka (Oryzias latipes), Chemosphere 59 (2005) 281-288.

[18] S. Meric, H. Selcuk, V. Belgiorno, Acute toxicity removal in textile finishing wastewater by Fenton's oxidation, ozone and coagulation-flocculation processes, Water Res. 39 (2005) 1147-1153.

[19] H. Yu, E. Nie, J. Xu, S. Yan, W.J. Cooper, W. Song, Degradation of diclofenac by advanced oxidation and reduction processes: kinetic studies, degradation pathways and toxicity assessments, Water Res. 47 (2013) 1909-1918.

[20] D.I. Kern, R.d.O. Schwaickhardt, G. Mohr, E.A. Lobo, L.T. Kist, E.L. 
Machado, Toxicity and genotoxicity of hospital laundry wastewaters treated with photocatalytic ozonation, Sci. Total Environ. 443 (2013) 566-572.

[21] D.D. Asouhidou, K.S. Triantafyllidis, N.K. Lazaridis, K.A. Matis, S.-S. Kim, T.J. Pinnavaia, Sorption of reactive dyes from aqueous solutions by ordered hexagonal and disordered mesoporous carbons, Micropor. Mesopor. Mat., 117 (2009) 257-267.

[22] USEPA, Short-time methods for estimating the chronic toxicity of effluent and receiving water to freshwater organisms, Office of Water, US EPA, NW Washington DC, 2002.

[23] APHA, Standard methods for the examination of water and wastewater, American Public Health Association/American water work Association/Water environment Federation, Washington D.C., USA, 1998.

[24] H. Kong, H. Wu, Pretreatment of textile dyeing wastewater using an anoxic baffled reactor, Bioresour. Technol. 99 (2008) 7886-7891.

[25] D.D. Asouhidou, K.S. Triantafyllidis, N.K. Lazaridis, K.A. Matis, Adsorption of Remazol Red 3BS from aqueous solutions using APTES- and cyclodextrin-modified HMS-type mesoporous silicas, Colloids Surf. A 346 (2009) 83-90.

[26] R.F. Nogueira, M.C. Oliveira, W.C. Paterlini, Simple and fast spectrophotometric determination of $\mathrm{H}_{2} \mathrm{O}_{2}$ in photo-Fenton reactions using metavanadate, Talanta 66 (2005) 86-91.

[27] OECD, OECD guidelines for testing of chemicals. Guideline no. 203: fish, acute toxicity test, 1992a.

[28] J.-S. Guo, A.A. Abbas, Y.-P. Chen, Z.-P. Liu, F. Fang, P. Chen, Treatment of landfill leachate using a combined stripping, Fenton, SBR, and coagulation process, J. Hazard. Mater. 178 (2010) 699-705.

[29] J. Garcia-Montano, N. Ruiz, I. Munoz, X. Domenech, J.A. Garcia-Hortal, F. Torrades, J. Peral, Environmental assessment of different photo-Fenton approaches for commercial reactive dye removal, J. Hazard. Mater. 138 (2006) 218-225.

[30] H. Lee, M. Shoda, Removal of COD and color from livestock wastewater by the Fenton method, J. Hazard. Mater. 153 (2008) 1314-1319.

[31] C.A. Martinez-Huitle, E. Brillas, Decontamination of wastewaters containing synthetic organic dyes by electrochemical methods: A general review, Appl. Catal. B-Environ. 87 (2009) 105-145. 
[32] C.S.D. Rodrigues, L.M. Madeira, R.A.R. Boaventura, Optimization and economic analysis of textile wastewater treatment by photo-Fenton process under artificial and simulated solar radiation, Ind. Eng. Chem. Res. 52 (2013) 13313-13324.

[33] D. Vogna, R. Marotta, R. Andreozzi, A. Napolitano, M. d'Ischia, Kinetic and chemical assessment of the $\mathrm{UV} / \mathrm{H}_{2} \mathrm{O}_{2}$ treatment of antiepileptic drug carbamazepine, Chemosphere 54 (2004) 497-505.

[34] P. Calza, V.A. Sakkas, C. Medana, C. Baiocchi, A. Dimou, E. Pelizzetti, T. Albanis, Photocatalytic degradation study of diclofenac over aqueous $\mathrm{TiO} 2$ suspensions, Appl. Catal. B-Environ. 67 (2006) 197-205.

[35] R.F. Dantas, M. Canterino, R. Marotta, C. Sansa, S. Esplugas, R. Andreozzi, Bezafibrate removal by means of ozonation: Primary intermediates, kinetics, and toxicity assessment, Water Res. 41 (2007) 2525-2532.

[36] L. Prieto-Rodriguez, I. Oller, N. Klamerth, A. Agueera, E.M. Rodriguez, S. Malato, Application of solar AOPs and ozonation for elimination of micropollutants in municipal wastewater treatment plant effluents, Water Res. 47 (2013) 1521-1528.

[37] N. De la Cruz, L. Esquius, D. Grandjean, A. Magnet, A. Tungler, L.F. de Alencastro, C. Pulgarin, Degradation of emergent contaminants by $\mathrm{UV}, \mathrm{UV} / \mathrm{H}_{2} \mathrm{O}_{2}$ and neutral photo-Fenton at pilot scale in a domestic wastewater treatment plant, Water Res. 47 (2013) 5836-5845.

[38] Y. Gao, Y. Ji, G. Li, T. An, Mechanism, kinetics and toxicity assessment of OH-initiated transformation of triclosan in aquatic environments, Water Res. 49 (2014) 360-370.

[39] B.J. Majer, B. Laky, S. Knasmuller, F. Kassie, Use of the micronucleus assay with exfoliated epithelial cells as a biomarker for monitoring individuals at elevated risk of genetic damage and in chemoprevention trials, Mutat. Res. 489 (2001) 147-172.

[40] N.P. Singh, M.T. McCoy, R.R. Tice, E.L. Schneider, A simple technique for quantitation of low-levels of DNA damage in individual cells, Exp. Cell Res. 175 (1988) 184-191.

[41] G. Li, T. An, X. Nie, G. Sheng, X. Zeng, J. Fu, Z. Lin, E.Y. Zeng, Mutagenicity assessment of produced water during photoelectrocatalytic degradation, Environ. Toxicol. Chem. 26 (2007) 416-423. 


\section{Figure captions:}

Fig. 1. Chemical formula of dye 3BS.

Fig. 2. Effects of Fenton reagent ratio on synthetic effluent treatment by Fenton and Fenton-coagulation processes: (a) degradation of 3BS, (b) removal of COD. $\mathrm{pH}_{0}=3$, $\left[\mathrm{Fe}^{2+}\right]_{0}=0.36 \mathrm{mM}, \mathrm{C}_{0}, 3 \mathrm{BS}=10 \mathrm{mg} / \mathrm{L}, \mathrm{COD}_{0}=100 \mathrm{mg} / \mathrm{L}$.

Fig. 3. Decomposition of $\mathrm{H}_{2} \mathrm{O}_{2}$ in the synthetic effluent during the Fenton and Fenton-coagulation processes at different Fenton reagent ratios. $\mathrm{pH}_{0}=3,\left[\mathrm{Fe}^{2+}\right]_{0}=$ $0.36 \mathrm{mM}, \mathrm{C}_{0,3 \mathrm{BS}}=10 \mathrm{mg} / \mathrm{L}, \mathrm{COD}_{0}=100 \mathrm{mg} / \mathrm{L}$.

Fig. 4. Genotoxicity bioassays of $25 \%$ diluted synthetic effluent during the Fenton-coagulation process at different Fenton reagent ratios (3:1, 6:1 and 12:1) (a) MN assay, (b) comet assay. $\mathrm{pH}_{0}=3,\left[\mathrm{Fe}^{2+}\right]_{0}=0.36 \mathrm{mM}, \mathrm{C}_{0}, 3 \mathrm{BS}=10 \mathrm{mg} / \mathrm{L}, \mathrm{COD}_{0}=$ $100 \mathrm{mg} / \mathrm{L}, \mathrm{pH}_{\mathrm{t}}=7 . *$ Statistically significant differences according to $\mathrm{NC}(\mathrm{p}<0.05)$.

Fig. 5. Evolution of COD for different Fenton reagent ratios on real effluent treatment during Fenton and Fenton-coagulation processes. $\mathrm{pH}_{0}=3,\left[\mathrm{Fe}^{2+}\right]_{0}=0.36$ $\mathrm{mM}, \mathrm{COD}_{0}=96.1 \mathrm{mg} / \mathrm{L}$.

Fig. 6. Decomposition of $\mathrm{H}_{2} \mathrm{O}_{2}$ in the real effluent during the Fenton and Fenton-coagulation processes at different Fenton reagent ratios. $\mathrm{pH}_{0}=3,\left[\mathrm{Fe}^{2+}\right]_{0}=$ $0.36 \mathrm{mM}, \mathrm{COD}_{0}=96.1 \mathrm{mg} / \mathrm{L}$.

Fig. 7. Genotoxicity bioassays of $75 \%$ diluted real effluent during the Fenton-coagulation process for different Fenton reagent ratios (6:1 and 12:1), (a) MN assay, (b) comet assay. $\mathrm{pH}_{0}=3,\left[\mathrm{Fe}^{2+}\right]=0.36 \mathrm{mM}, \mathrm{COD}_{0}=96.1 \mathrm{mg} / \mathrm{L}, \mathrm{pH}_{\mathrm{t}}=7$. * Statistically significant differences according to NC ( $<<0.05)$. 


\section{Table legends:}

Table 1. Water quality of the real dye effluent.

Table 2. Acute toxicity of synthetic effluent during the Fenton-coagulation process at different Fenton reagent ratios $\left(\mathrm{pH}_{0}=3,\left[\mathrm{Fe}^{2+}\right]_{0}=0.36 \mathrm{mM}, \mathrm{C}_{0}, 3 \mathrm{BS}=10 \mathrm{mg} / \mathrm{L}\right.$, $\mathrm{COD}_{0}=100 \mathrm{mg} / \mathrm{L}, \mathrm{pH}_{\mathrm{t}}=7$ ). Both $\mathrm{NC}$ and Fenton reagent control with $100 \%$ survival

Table 3. Acute toxicity of real effluent during the Fenton-coagulation process at different Fenton reagent ratios $\left(\mathrm{pH}_{0}=3,\left[\mathrm{Fe}^{2+}\right]_{0}=0.36 \mathrm{mM}, \mathrm{COD}_{0}=96.1 \mathrm{mg} / \mathrm{L}, \mathrm{pH}_{\mathrm{t}}=\right.$ 7). Both NC and Fenton reagent control with 100\% survival

Color artwork: on the Web only 
Table 1. Water quality of the real dye effluent.

\begin{tabular}{llll}
\hline Parameter & Unit & Effluent & $\begin{array}{l}\text { Maximum } \\
\text { allowable value }\end{array}$ \\
\hline $\mathrm{pH}$ & - & 7.5 & $6-9$ \\
Color & dilution times & 30 & 70 \\
COD & mg/L & 96.1 & 50 \\
BOD & mg/L & 20 & 25 \\
BOD/COD ratio & - & 0.21 & - \\
SS & & 53.4 & 60 \\
TP & mg/L & 1.1 & 1.0 \\
TN & mg/L & 67.7 & 20 \\
TOC & mg/L & 61.3 & 12 \\
NH ${ }_{4}^{+}-\mathrm{N}$ & & 20.6 & - \\
\hline
\end{tabular}

- means not exist 
Table 2. Acute toxicity of synthetic effluent during the Fenton-coagulation process at different Fenton reagent ratio $\left(\mathrm{pH}_{0}=3,\left[\mathrm{Fe}^{2+}\right]_{0}=0.36 \mathrm{mM}, \mathrm{C}_{0}, 3 \mathrm{BS}=10 \mathrm{mg} / \mathrm{L}, \mathrm{COD}_{0}=\right.$ $100 \mathrm{mg} / \mathrm{L}, \mathrm{pH}_{\mathrm{t}}=7$ ). Both $\mathrm{NC}$ and Fenton reagent control with $100 \%$ survival

\begin{tabular}{|c|c|c|c|c|}
\hline \multirow[t]{2}{*}{ Treatment time (h) } & \multirow[t]{2}{*}{ Dilution (\%) } & \multicolumn{3}{|c|}{ Mortality rate (\%) (Fenton reagent ratio) } \\
\hline & & $3: 1$ & $6: 1$ & $12: 1$ \\
\hline 0 & 100 & $8 \pm 5$ & $8 \pm 5$ & $8 \pm 5$ \\
\hline \multirow[t]{4}{*}{0.5} & 100 & $23 \pm 5$ & $65 \pm 6$ & $25 \pm 6$ \\
\hline & 75 & 0 & $30 \pm 8$ & $8 \pm 5$ \\
\hline & 50 & 0 & $8 \pm 5$ & 0 \\
\hline & 25 & 0 & 0 & 0 \\
\hline \multirow[t]{2}{*}{1} & 100 & $23 \pm 5$ & $20 \pm 8$ & 0 \\
\hline & 75 & 0 & 0 & 0 \\
\hline \multirow[t]{2}{*}{2} & 100 & $23 \pm 5$ & 0 & 0 \\
\hline & 75 & 0 & 0 & 0 \\
\hline \multirow[t]{2}{*}{3} & 100 & $25 \pm 6$ & 0 & 0 \\
\hline & 75 & 0 & 0 & 0 \\
\hline \multirow[t]{2}{*}{4} & 100 & $26 \pm 5$ & 0 & 0 \\
\hline & 75 & 0 & 0 & 0 \\
\hline
\end{tabular}


Table 3. Acute toxicity of real effluent during the Fenton-coagulation process at different Fenton reagent ratios $\left(\mathrm{pH}_{0}=3,\left[\mathrm{Fe}^{2+}\right]_{0}=0.36 \mathrm{mM}, \mathrm{COD}_{0}=96.1 \mathrm{mg} / \mathrm{L}, \mathrm{pH}_{\mathrm{t}}=\right.$ 7). Both NC and Fenton reagent control with $100 \%$ survival

\begin{tabular}{cccc}
\hline Treatment procedure & Time (h) & Dilution (\%) & Mortality rate (\%) \\
\hline Raw real wastewater & 0 & 100 & $17 \pm 6$ \\
{$\left[\mathrm{H}_{2} \mathrm{O}_{2}\right]:\left[\mathrm{Fe}^{2+}\right]=6: 1$} & 1 & 100 & $30 \pm 8$ \\
& 2 & 100 & 0 \\
& 3 & 100 & 0 \\
& 4 & 100 & 0 \\
{$\left[\mathrm{H}_{2} \mathrm{O}_{2}\right]:\left[\mathrm{Fe}^{2+}\right]=12: 1$} & 1 & 100 & 0 \\
& 2 & 100 & 0 \\
& 3 & 100 & 0 \\
& 4 & 100 & 0
\end{tabular}


Figure 1

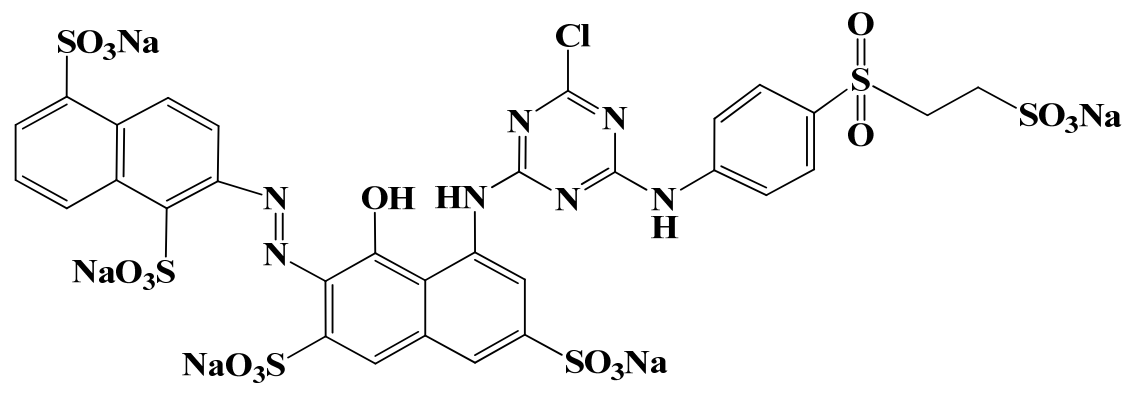


Figure 2
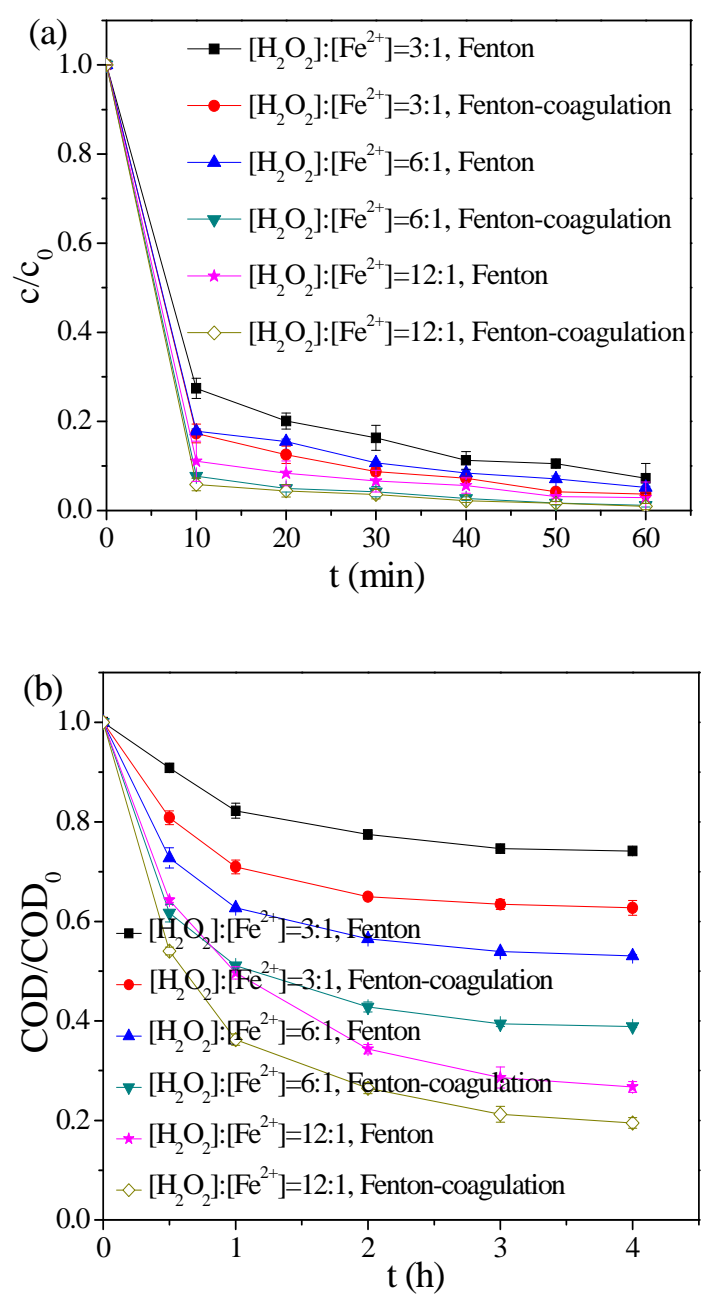
Figure 3

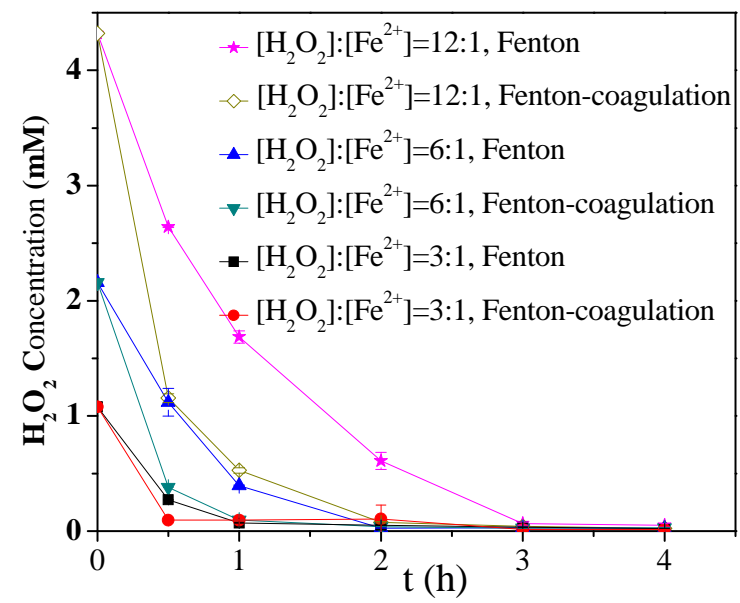


Figure 4
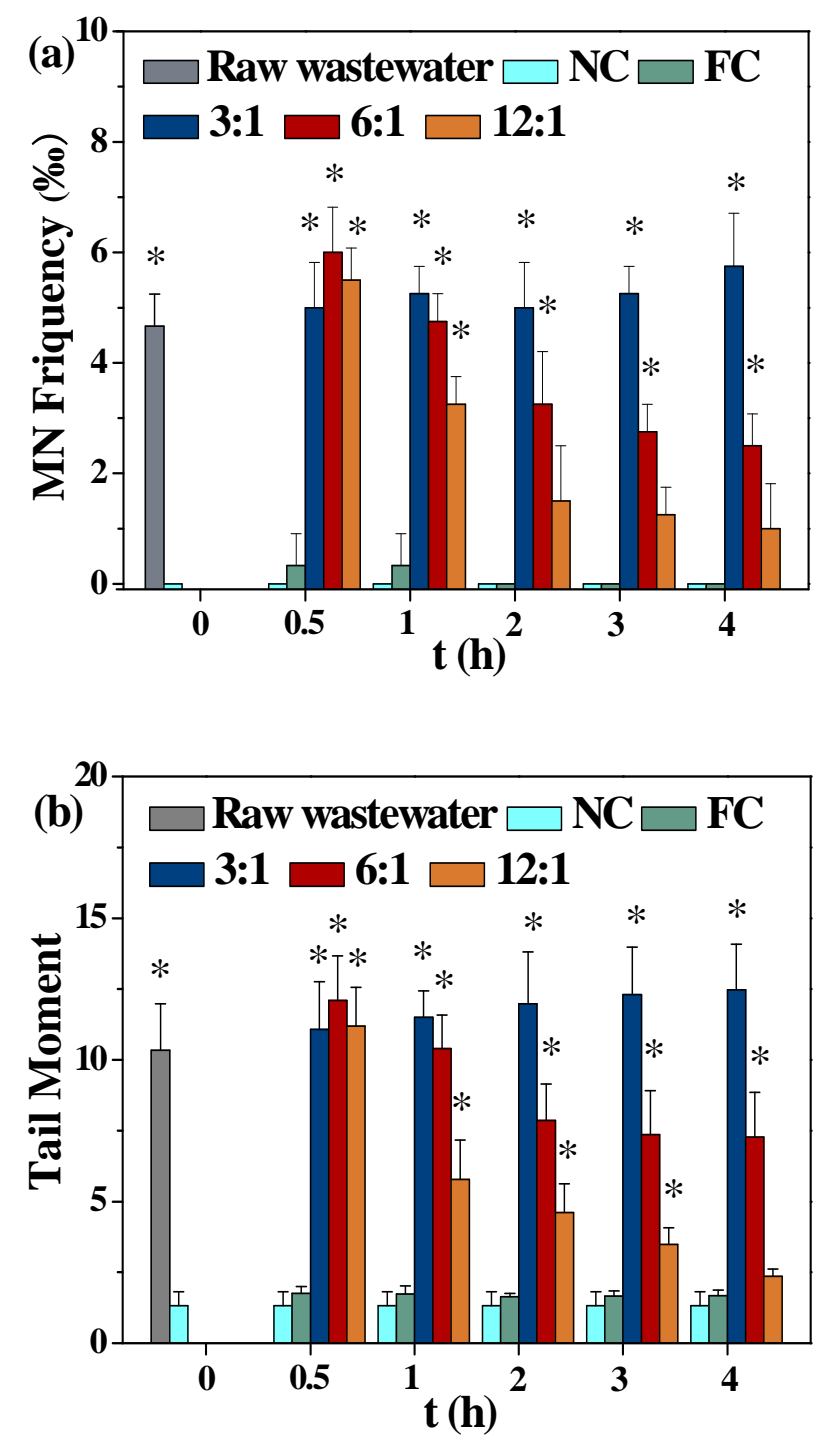
Figure 5

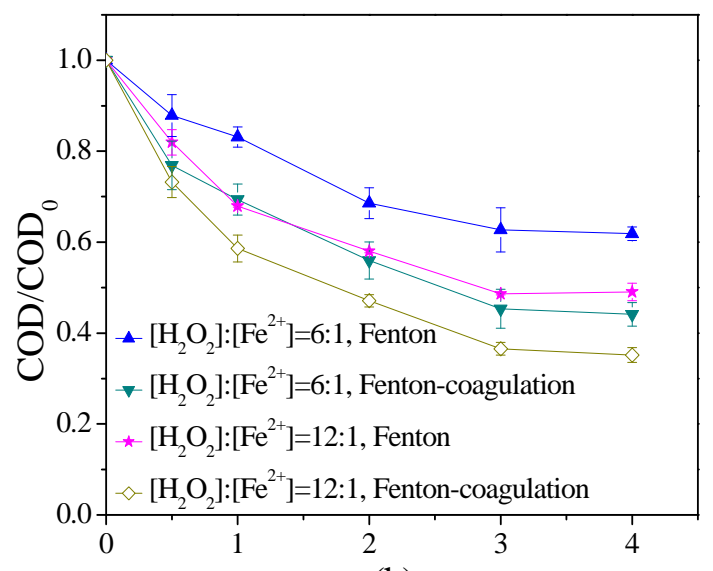

t (h) 
Figure 6

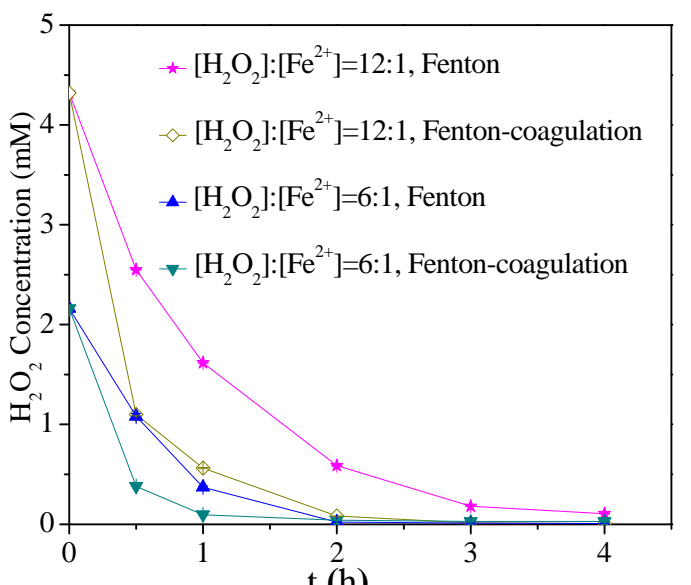

t (h) 

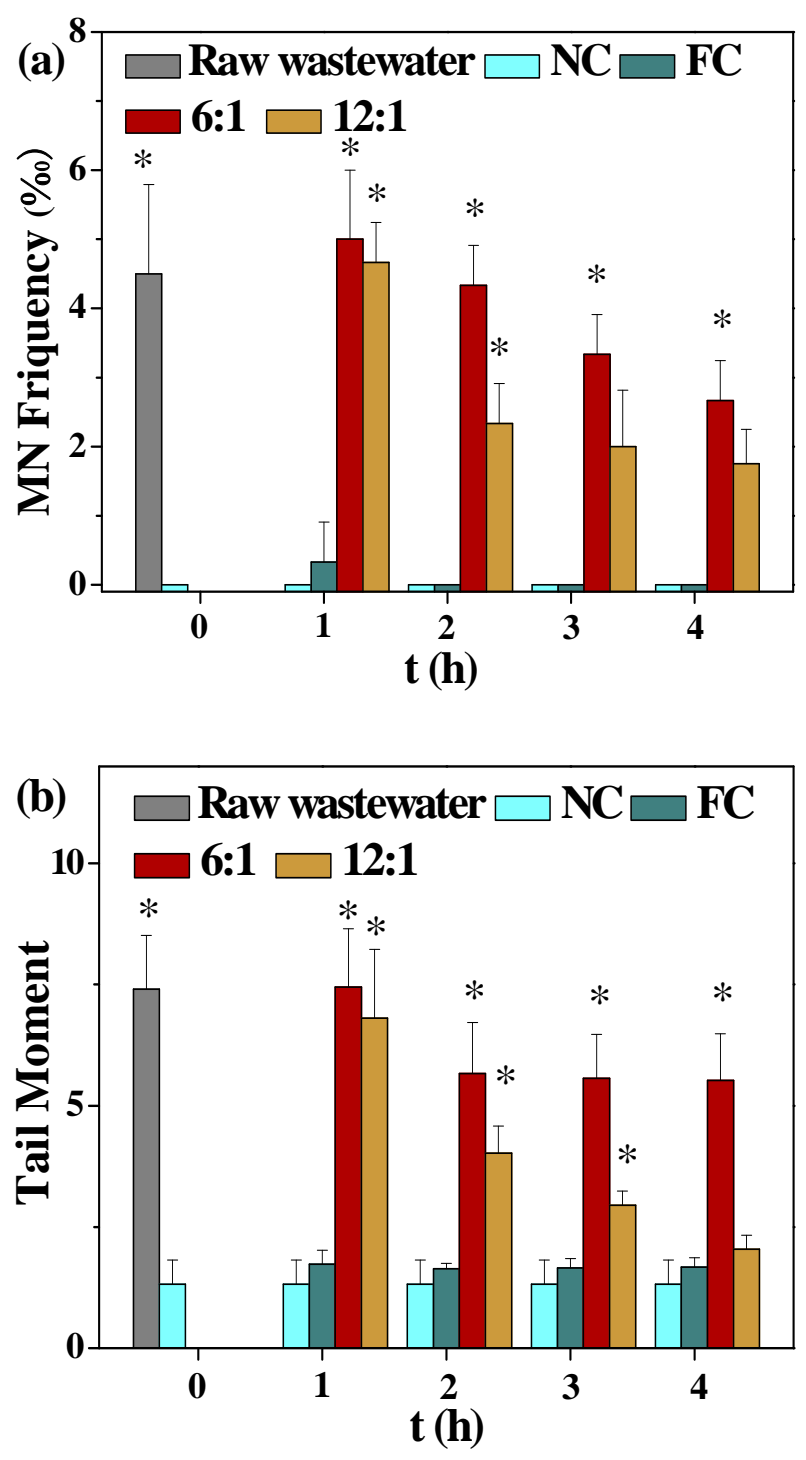